\title{
Finding the back of the net: Networks and migrant recruitment in Norwegian football
}

\author{
Richard Elliott \\ Southampton Solent University \\ and \\ Erik Gusterud \\ Norwegian School of Sport Sciences
}

\section{Abstract}

The intention of this paper is to analyse the role that networks play in the recruitment of a group of male migrant professional footballers employed by clubs based in Norway's top professional football league - the Tippeligaen. Based upon a series of semi-structured interviews conducted with migrants and recruiters and synthesising concepts derived from the sociology of sport and the broader study of migration, the analysis identifies that the recruitment of migrant workers to Tippeligaen clubs reflects a mix of both formal and informal processes. Whilst agents operate as key actors in the mobilisation of labour, the analysis shows how recruitments in this particular athletic context are also dependent on processes of human mediation facilitated by a series of informal interdependent networks of relationships.

Keywords: Migration; networks; recruitment; sport; football. 


\section{Finding the back of the net: Networks and migrant recruitment in Norwegian football}

Research into the area of athletic labour migration has grown significantly in the last three decades. Whilst the early works of scholars such as John Bale (1991) and Joseph Maguire (1994) began to explore the intersection that exists between the areas of human geography and sociology as they relate to sport, it is more recently that the burgeoning study of migration in the athletic sphere has come to reflect a range of theories and concepts more commonly found in the broader migration literature. This has included the study of networks and their value in relation to recruitment and labour market experience for migrant workers. Research in this area has identified the ways in which recruitment is enabled via human mediation. More specifically, it has shown how, for some athletic workers, mutually beneficial recruitments can be facilitated through informal networks of interdependent relationships (see, for example, Elliott, 2014a, 2014b; Elliott and Maguire, 2008; Engh and Agergaard, 2013).

Research examining the value of networks in the recruitment of migrant workers has grown in recent years (see for example, Behtoui, 2008; Rainer and Siedler, 2009; McCollum and Apsite-Berina, 2014). This research has drawn attention to the role that family members and friends play in the transfer of information in respect of particular employment opportunities (Boyd, 1989). In these sorts of circumstances, members of networks are conceptualised as being personal contacts who are known to potential migrants prior to their seeking information in regards to employment (Granovetter, 1995). They are important because members of networks can broker relationships between future employees and employers. They can provide the employee with information about the job and the employer with information in respect of the potential employee's suitability for it (Meyer, 1991). In this way, informal contacts bound up in webs of interdependent social relationships can be crucial in generating routes into employment for migrants who may lack other means of entry into particular labour markets (McCollum and Apsite-Berina, 2014). 
Networks have been identified as being important in the recruitment of athletic workers into the labour markets of professional sports leagues. At first this might sound odd, given that the generally accepted reality of professional sport is that formal intermediaries play central roles in the mobilisation of athletes from one employer to another (Poli, 2010, 2014; Roderick, 2006). This may be true, to an extent. However, it should be borne in mind that it is only a very small minority of athletes employed in the most prominent leagues who will likely rely on an agent to broker their employment contracts. The majority of migrant workers employed by professional sports clubs operate in an environment that is far removed from the wealth and glamour of their respective sports established leagues. Given their more limited financial capabilities, these types of migrants have been seen to draw on networks as they attempt to avoid the costs associated with retaining an agent (Elliott and Maguire, 2008, 2011). Outside of the established core leagues, clubs also seek alternative ways to identify and recruit foreign talent. With limited budgets for the scouting and analysis of potential foreign recruits, clubs situated in peripheral economies rely on the flows of information that circulate within networks to identify, learn about and recruit migrant workers (Bale, 1991; Elliott and Maguire, 2011).

Whilst a small but growing number of studies have sought to examine the significance of networks in the recruitment of migrant workers into professional sports leagues, little research has sought to analyse the significance of these particular types of networks in facilitating migrant recruitment in men's professional football. To that end, the intention of this paper is to analyse the role that networks play in influencing the career trajectories of a group of male migrant professional footballers employed by clubs based in Norway's top division - the Tippeligaen. The analysis is underpinned by qualitative data, collected from the migrants themselves as well as other key actors in the recruitment of foreign talent. A total of 14 semi-structured interviews were conducted with players, coaches and sporting directors at a range of clubs in the league. Examining the recruitment of migrant workers from the perspective of both players and recruiters is important because it highlights the interdependent bonds that exist between these groups, and others enmeshed in their respective 
networks. Examining the recruiting process from multiple perspectives enhances understanding of the ways in which networks can be used in the mobilisation of migrant labour.

The paper begins by exploring the various approaches taken to better understand the role that networks play in the mobility of workers within and beyond sport. The discussion here predominantly revolves around the important role that networks can play in enabling the movements of certain types of workers. The second section of the paper then provides some contextual background in respect of the Norwegian Tippeligaen. Understanding the particularities of this sporting environment is fundamental when contextualising the importance of networks for the players and recruiters employed within it. Following a brief discussion of methods, in the third section, qualitative data is presented in respect of the case study. Here, the perceptions of those players, coaches and sporting directors actively bound up in recruiting processes are examined. The concluding section then discusses the importance of networks in defining the career trajectories of those athletic workers employed in the Norwegian Tippeligaen, before making some recommendations for future research in this area.

\section{Networks and migrant recruitment}

The role of networks in brokering the relationship between employers and potential migrant employees has been recognised for some time (see, for example, Boyd, 1989; Meyer, 2001; Shah and Menon, 1999). Much of the research in this area has identified the benefits that exist when informal contacts are able to connect employers with potential migrant employees. The process of recruiting staff inevitable incurs costs when vacant positions have to be advertised and applicants interviewed. Recruiting via networks eliminates the need for these types of searches and the screening of potential candidates as information obtained from existing contacts is used to validate the suitability of workers for vacant posts (McCollum and Apsite-Berina, 2014). Existing migrant employees are particularly useful when recruitments are conducted in this way. Organisations will likely only take seriously those recommendations made by 
what they view to be 'good' employees, as these types of workers are likely to recommend recruits with similar characteristics to themselves. Since members of networks tend to share similar attributes (McPherson et al, 2001), recruitments that are conducted via largely homogenous networks where the members share a range of sociodemographic, behavioural and intrapersonal characteristics enhance the likelihood of organisations reproducing a workforce that can meet the demands of the job.

Additionally, information passed through networks can also be used to provide potential migrants with detailed and reliable information in regards to the specific demands of a role and, beyond that, the broader social, cultural and geographical environment in which it is based. For example, Meyer's (2001) research identifies how 'bridgeheads' circulate information relating to potential employment opportunities in particular locations. Bridgeheads, Meyer argues, are migrants who have already experienced the migration process themselves, and who, by generating flows of information to the potential migrant employee, can mobilise additional migrations within similar interdependent networks to their own. For some potential migrants, these flows of information are crucial, particularly where access to employment markets might be more difficult.

The importance of migrant networks varies across labour markets. That is to say that in some labour markets the ability to tap into a network of contacts is of greater significance than it may be in another (Marshall, 1989). Moreover, networks have been identified as being more important for certain types of workers - typically the less educated or qualified, who may not possess adequate language proficiency or knowledge in regards to particular labour markets (Sumption, 2009). Whilst these trends have been traced in a number of different employment contexts (Chua, 2011; Giulietti et al, 2013), similar patterns can be identified in the labour markets of various professional sports leagues (Elliott and Maguire, 2008; Elliott, 2014b). Only a relatively small minority of elite athletes employed in the most prestigious leagues will ever operate at a level whereby their movements are exclusively managed by agents or other formal intermediaries. For many athletes who, in the context of elite sport, might be described as being of lesser ability, the capacity to retain the services of an agent 
may be more limited and, thus, the ability to tap into networks forms a fundamental part of their employment strategy.

Research has shown this to be the case in professional ice hockey where players employed in leagues located outside of the game's established core rely on their networks for information in regards to potential employment opportunities. For example, in their examination of recruiting processes in the British Elite Ice Hockey League, Elliott and Maguire (2008) identified how the gaining of knowledge about vacant positions in teams rarely involved the intervention of a professional employment consultant, such as an agent. Instead, flows of information were facilitated by informal communications, maintained by distinct contact groups, in a series of informal networks of interdependent relationships. Networks of contacts were used as a resource through which information valuable to potential migrants could be channeled. Thus, players acquired their employment via a series of interdependent connections and, in this particular employment context, social and professional relationships could be seen to constitute the most effective means towards migrant recruitments.

Beyond the athletes themselves though, the value of networks for recruiters has also been identified. For example, Bale's (1991) study of the recruitment of student track and field athletes to American Universities highlighted the importance of networks for recruiters when identifying potential migrant recruits. In this particular sub-elite sporting environment, recruiting systems were often comprised of well-planned networks of informal contacts in particular donor locations. Those universities that had benefited from some of the most significant recruiting successes had done so as a consequence of the quality of the network of contacts that had been developed and utilised. Similar findings can be identified in the work of Tiesler (2014), where she examined the transnational movements of elite female footballers and identified the significance of networks as one strategy in the recruitment of these types of athletic workers. McCree's (2014) analysis of the migrations of female footballers from Trinidad and Tobago to the United States illustrates similar trends. 
The significance of recruiting via networks in what might be described as more peripheral sporting environments has been explained in terms of professionalism - that is to say that as the quality of a league reduces and it becomes regarded as less 'professional', so, it is argued, the necessity to recruit via informal mechanisms increases (Tiesler, 2014). It is contended that these sorts of trends may be identifiable in men's professional football, a sport with an increasingly complex global architecture. Whilst, in the last three decades, a small number of highly visible, commercially powerful and largely analogous leagues have appeared, the spatial dispersal of the professional games cultural and economic capital has been highly uneven. As a result, significant differences are now identifiable between the games established core economies and those situated outside of the core. It is to a discussion of one of these 'outsider' leagues that the paper now turns.

\section{Migration and Norwegian football}

The migrations of professional footballers have become one of the most ubiquitous markers of the globalisation of sport in the $21^{\text {st }}$ Century. Indeed, the magnitude, composition and direction of migration in the game has meant that there are now few parts of the globe that are not affected by the movements of players, managers, coaches and other support staff. In many cases these migrations follow the trends identifiable in the movement of workers in various other spheres of employment - in this respect, movement often occurs towards what one might term the core economies (Bohning, 1984; Fischer, Reiner and Straubhaar, 1997; Magee and Sugden, 2002).

Professional football's core economies are located in Western Europe and comprise the 'big-five' European leagues (English Premier League, Spanish La Liga, Italian Serie A, German Bundesliga, French Ligue 1). These leagues, and some of the teams within them, generally command the greatest media interest, the broadest (sometimes global) fan bases and the highest revenues. Not all of Europe's football leagues are located at or near the core, however. Like many facets of life in a globalised world, the globalisation of football has not been even over time. Political, economic and cultural factors have influenced the 
permeation of the global sport par excellence into different parts of Europe (and the world) at different times.

For example, in Norway the development of men's professional football occurred much later than in other parts of Europe and it was not until 1991 that Norwegian clubs were permitted to sign players to professional contracts (Gammelsæter, 2009). The 1990s saw rapid growth in the commercialisation and professionalisation of the game in Norway (Andersson and Carlsson, 2009; Hognestad, 2009). As a result, Norwegian football gained prominence during this period receiving wider recognition within the international football community as a result of national team success, which included qualification for the 1994, and the 1998 World Cups, as well as the 2000 European Championships (Hognestad, 2009; Jakobsen et al, 2009). Moreover, Norwegian clubs, particularly Rosenborg BK, achieved significant success in European competition during this period, participating eleven times in the group stage of the Union of European Football Association's (UEFA) Champions League between 1991 and 2004.

The period since the mid-2000s has been one of uncertainty for Norwegian football and one where the national team and Norwegian club sides have failed to qualify for major tournaments or competitions. Although the Norwegian national team was ranked as the second best team on the Fédération Internationale de Football Association's (FIFA) ranking system in 1993 and 1995, a lack of more recent success has resulted in Norway being ranked as low as the 67th best national team in the world (out of 209). At the same time, the position of Norway's top division - the Tippeligaen has also decreased. It is now ranked as the 26th best league in Europe (out of 54) in the UEFA ranking system. This means that the Tippeligaen is currently positioned as an outsider to European football's established core economies (Magee and Sugden, 2002).

Although the statistical ranking of the Norwegian league has declined in recent years, the success the game enjoyed in the 1990s triggered the basis for the economic expansion of professional football in Norway (Jakobsen et al, 2005). The Tippeligaen's financial turnover increased considerably in this 
period, rising from a modest €23.5 million in 1993 to €73 million in 2000. In 2007, the league's total turnover exceeded $€ 144$ million but, as a result of the financial crisis, since 2008 the capacity for Tippeligaen clubs to generate income has been more restricted. By 2014 the total turnover for the league's sixteen clubs was €155 million. However, many Tippeligaen clubs are struggling financially with several clubs reporting financial losses (NFF, 2013, 2014).

Despite the growth that the Tippeligaen enjoyed during the 1990s and 2000s, the financial strength of the league is weak when considered relatively the Europe's established core economies. As Figure 1 shows, the turnover of the Tippeligaen clubs is a fraction of that achieved in England, Germany, Spain, Italy and France. Income generation is restricted for Tippeligaen clubs for a number of reasons, none less than the sparsely populated environment in which the clubs operate. Norway has a total population of just 5 million people and, as a result, Tippeligaen clubs are limited in the funds they can generate from match day and commercial revenue streams. Additionally, domestic broadcasting revenues are tiny compared to Western Europe's established leagues. International broadcasting rights are even smaller, with little interest in the league outside of Norway.

\section{[Figure 1 about here]}

Irrespective of the financial strength of the Tippeligaen, however, like many other leagues in Europe in the last 20 years, the employment of foreign workers has become an established part of the recruiting practices of the league's clubs. Whilst only 13 foreign players were employed in the league in 1995, the recruitment of foreign players, mostly from other European countries, increased during the second half of the 1990s. As a result, 55 foreign players were playing for Tippeligaen clubs in 2000, 76 in 2004, 117 in 2008, 110 in 2013 and 104 in 2014 (Jakobsen et al, 2009; Transfermarkt.co.uk, 2014).

Currently, foreign players employed by Tippeligaen clubs originate from 29 different nations, where Denmark (14), Iceland (13), Sweden (11), Nigeria (10), Finland (8), Senegal (8) and the United States (8) represent the largest numbers. The majority of the migrant players employed in the league originate 
from locations that offer geographical proximity, analogous football development and fewer cultural differences (Molnar, 2006). Thus, a high proportion of the players have their origins from other Nordic/Scandinavian countries where similar political, economic and cultural climates exist. However, it is clear that many migrant players also originate from countries beyond Scandinavia, with African nations and the United States being particularly prominent.

Wherever migrant workers are recruited from, the Tippeligaen's numerical ranking and financial profile mean that it is situated as a middleranking league that sits well outside of the core of the European football system. This makes it an interesting case study when considering the mechanisms through which migrant workers are recruited. Indeed, both the numerical ranking and the league's financial strength may have an effect on the ways in which migrant workers are recruited (Elliott, 2012; Elliott and Maguire, 2008a). To establish if this is the case, the next part of the paper sets out the methods that were used to obtain the data.

\section{Method}

In an attempt to make sense of the mechanisms through which migrant workers are recruited to Tippeligaen clubs, a qualitative method was employed utilising individual, semi-structured, face-to-face interviews. Nine players, two sporting directors and three coaches $(n=14)$ were interviewed. With regards to players, the sample group was made up of eight different nationalities (Icelandic, Danish, Swedish, Finnish, Austrian, Nigerian, Senegalese and Canadian) with ages ranging from 19 to 36 (average age $=29$ ). The inclusion of players from a range of different nationalities was important to ensure that the sample group represented the spread of foreign players employed in the league and to establish if players recruited from disparate parts of the world were recruited in similar ways. All of the subjects had spent at least one season in the Tippeligaen between 2005 and 2014 and had played for a number of different clubs.

As with other studies of this nature one of the key methodological difficulties lay with gaining access to interviewees - a problem often exacerbated 
in the highly problematic (Roderick, 2014) and "impregnable world of professional football" (Magee and Sugden, 2002, p.423). For this study, access was gained via a series of gatekeepers at Tippeligaen clubs. A purposive approach was taken to sampling. Thus, current and former foreign players of Tippeligaen clubs, as well as sporting directors and coaches were selected. Whilst initial access was gained through gatekeepers, the sample was further constructed on a snowball basis where the interviewees introduced or recommended the researcher to new participants until no further respondents could be identified.

All of the interviews were conducted in Norway and most of the sample group spoke good English, however, some interviews were conducted in native languages including Norwegian, Swedish and Danish. Whilst translation-related choices may impact on the validity of the research, the data were translated into English by one of the authors who has an intimate knowledge of Scandinavian languages and culture. Thus, obtaining conceptual equivalence was not deemed to be a significant issue with respect to the validity of the data. The respondents were asked a range of questions that related to recruiting mechanisms. For the players, these included questions relating to their knowledge of the Tippeligaen prior to arrival, how they became aware of playing opportunities, the role of agents, and the significance of networks in the recruiting process. Recruiters were asked questions relating to the mechanics of recruiting players to the Tippeligaen, the scouting process, the role of agents and knowledge generation.

Once completed, the interviews were transcribed verbatim and a thematic analysis was conducted. This analysis required the data to be coded using processes of open and axial coding. As the data were coded it was possible to identify a number of convergent themes for discussion. It is to these themes that the paper now turns.

Networks and recruitment to the Tippeligaen: The players' perspectives

When interviewing migrant players employed by Tippeligaen clubs it became clear that informal networks of interdependent contacts could be important when gaining knowledge about potential employment opportunities in the 
league. However, unlike some other spheres of employment where networks have been seen to constitute the most effective means by which certain workers can access particular labour markets (Chua, 2011; Sumption, 2009), the utilisation of networks in gaining employment for this group of professional footballers represented a mix of more and less formal approaches (Agergaard and Ryba, 2014; Engh and Agergaard, 2013). Agents represented all of the players interviewed; yet those agents did not always identify playing opportunities. On occasion, information relating to potential employment opportunities flowed through a series of interdependent relationships identifiable in the players' networks. As one player put it, "if you know a lot of people then there will also come a lot of [playing] opportunities." Other player's made similar observations. One commented that, "you need contacts to help you get opportunities at new clubs", whilst another suggested, "contacts might help you to find a new club ... networks are like a short-cut."

Networks worked in different ways to facilitate the recruitments of foreign workers to Tippeligaen clubs. In some cases, bridgeheads (Meyer, 2001) could be seen to act as conduits in facilitating flows of information about potential employment opportunities to players and the suitability of players for vacant positions at clubs. As one player put it, "I ended up in Tippeligaen because a former player that I had played together with in Iceland recommended me to the club." Another player discussed how a connection between the coaching staff at his former and current club had facilitated a flow of information in respect of a potential opportunity. He commented:

When I was at [former club] they had a German coach who had a good relationship with my [current] manager, so they spoke together... it was because the managers have a good relationship that I became aware of the opportunity to play in Norway.

Other player's discussed recruitment in similar terms. For example, when asked how a club had been made aware of his suitability for employment, another player discussed the manner in which a former teammate had "told the club that they should have a look at him." This introduction ultimately resulted in the player being signed. 
What these recruitments show, is that formal mediators are not always active in facilitating flows of information in respect of potential employment opportunities and the suitability of workers for them. Rather, these recruitments are based on personal recommendations and the information that flows through the players' networks. Indeed, a number of the players also commented on how they had used their own networks to facilitate opportunities for other players. As one player put it, "I have opened doors for many players plenty of times." Another player discussed the role that he had played in the recruitment of migrant players to clubs:

I have also helped several players in my career to come to football clubs. It may be that I know a coach or a sporting director in a club and that I then know a player who might stand without a contract, which I then recommend ... I think it's common in the football world to help one another so there is a lot of talk between players and coaches. I think players often recommend former teammates if you think he's good.

This example not only demonstrates how mutually beneficial recruitments can occur as the result of human mediation, but also how recruitments that are conducted via networks potentially enhance the likelihood of organisations reproducing a workforce that can meet the demands of the job (McPherson et al, 2001).

All of the players interviewed were acutely aware of the importance of the connections that existed in networks when brokering relationships with potential employers. Yet, unlike other athletic migrants who have been seen to negotiate their migrations without the intervention of a formal intermediary (Elliott and Maguire, 2008, 2011), the players interviewed as part of this study were also aware of the importance of their agents. In some cases, it was the player's agent, utilising their own network of contacts, who identified a potential employment opportunity. However, in other cases, where players were made aware of opportunities via their own networks, the role of the agent was restricted to dealing with clubs, particularly in respect to contractual issues. Therefore, whilst agents were not always involved in the identification of the employment opportunities themselves, they were still viewed by players, and as 
the next section of the paper will show - recruiters, as central actors in the mobilisation of migrant labour.

\section{The recruiters' perspective}

From the perspective of those individuals responsible for the recruitment of migrant workers, networks were viewed as being very important. For recruiters, networks were crucial in supplementing the information passed to them in respect of potential recruits from agents. Sporting directors and coaches pointed to the significance of having a broad and global network of contacts, which had often been built up over a number of years working in professional football. With respect to gaining knowledge about and recruiting foreign players, it appeared that whilst some information in respect of potential recruits flowed through informal networks, recruiters at Tippeligaen clubs were still heavily reliant on the information provided to them by agents - particularly in respect of those migrants recruited from clubs located outside of Europe. This is not unsurprising taking into account the financial strength of Norwegian football where very few clubs have their own scouts who can engage in extensive international scouting operations. According to one respondent, scouting among Tippeligaen clubs appeared to be both "abandoned and undervalued", mainly, he believed, as a result of limited finances, but also because of a lack of tradition.

Thus, networks were highly significant with respect to the process of gaining knowledge about and recruiting foreign players to Tippeligaen clubs. As one sporting director commented:

The recruitment of foreign players depends heavily on well-established and good networks ... you will get a lot of inputs from different sources, including current or former players, managers, coaches, sporting directors, scouts and agents.

A head coach made a similar observation in regards to the importance of networks in the recruitment of players: 
Networks are really important. I know many agents, journalists, former teammates, former coaches, former managers which you are sometimes talking to on the phone. We're often talking about players and it could be that you're getting tips from one of your contacts ... you will become aware of a lot of players through your network, through talking to people.

Like the recruiters in Bale's (1991) study, coaches argued that it was "absolutely crucial to have a large network of contacts" in order to be successful in the transfer market. Clubs, via their staff, often had well-established connections in several specific locations abroad with contacts made up of a mixture of both formal intermediaries such as agents and "people that are in a more neutral position."

Neutrality was one of the key prerequisites in the significance of networks for recruiters. Whilst players, irrespective of how they became aware of employment opportunities, relied on agents in order to mediate their migrations, clubs tapped into the flows of information via networks to validate the information being provided to them by agents. As one sporting director put it, "agents are almost always involved, but you're often using more personal contacts to gain knowledge about players in addition to what the agents are telling you." Indeed, all of the coaches and sporting directors interviewed had doubts about the integrity of agents, arguing that they could not be trusted, largely due to their perceived mercenary motives and bias in respect of their clients. As one head coach put it, "you will get a lot of enquiries from agents that are trying to make you sign a player that is probably not as good as he's saying."

Existing contacts, therefore, performed a crucial role in the validation of information provided in respect of potential recruits from agents. As one sporting director put it, "the more personal networks have helped to uncover some truths." One of the head coaches expanded on this idea when discussing the importance of networks in the recruitment of migrant workers:

I think it is very important to quality assure the input you get from agents and other people, because if you speak to an agent, their player is the world's best player for you to sign, so I think these more personal networks are important in making sure what the agents are telling you is reliable or 
not; if it's a reason to go any further with that player or not.

Another head coach made similar observations in regards to the importance of using networks as opposed to trusting the information provided by agents. He commented:

I used all possible people that I thought knew anything about the player to build a foundation and a clear picture of the player. It was to assure quality, and you will often try to use more neutral sources than agents to get input and opinions about players you might want to sign.

Within these networks, players were seen to be particularly important sources of information. Coaches and sporting directors discussed how players could provide detail in regards to "how the person is" and how they think they will "fit into the squad, the club and the country." As one coach put it, "players often have a better knowledge about [a player's] personality and so on, as well as his football specific abilities." This would seem a sensible approach to knowledge generation, one that is built upon the premise that members of networks often share a range of sociodemographic, behavioural and intrapersonal characteristics (McPherson et al, 2001).

As in other sectors of the labour market, networks of interdependent contacts were used to assure the quality of information provided by agents and to validate the suitability of workers for vacant posts (McCollum and ApsiteBerina, 2014). This latter point was particularly important for the coaches and sporting directors of Tippeligaen clubs. Indeed, all of the coaches and sporting directors interviewed considered the use of networks advantageous since recruitment through trusted friends, colleagues or former or current players provided what they believed was unbiased information about potential recruits. Moreover, given the nature of competitive professional sport, players were seen to recommend only those potential migrants who they felt possessed the abilities to enhance the performance of the team. Thus, players recommended recruits who they were sure would meet the demands of the job (Lin, 1999) 
Although some studies have argued that networks are used as a means by which clubs and players can avoid agent costs (Elliott and Maguire, 2008, 2011), it appeared that agents were almost always involved in the recruitment of foreign players to Tippeligaen clubs. Despite their involvement, it became clear that recruiters relied on networks in order to validate the quality of the information they received from agents. Ensuring quality of information in respect of potential recruits was deemed to be essential in a sporting context where, as one respondent put it, clubs cannot afford to "recruit wrong players". The risk of doing so by simply trusting the information provided by agents appeared to be too great for the recruiters examined in this study.

\section{Conclusion}

The findings from this analysis show that networks do have a role to play in the recruitment of migrant workers to clubs based in the Norwegian Tippeligaen. However, unlike other sectors of the labour market where they have been seen to constitute the most effective or only means by which migrant workers can secure employment, in the context of professional football, in a middling league by European standards, recruitments are facilitated by a mix of formal and informal approaches and one where agents still perform central roles in the mobilisation of labour. Agents did not always identify playing opportunities. However, based on the data in this analysis, they were nearly always involved in mediating the move from one club to another - even if that involvement was limited to dealing with contractual issues.

In the cases where agents had not identified a playing opportunity, information relating to employment could be seen to flow via the players' networks. Players were not reliant on these networks to identify employment opportunities, yet, on occasion, their enmeshment in a complex series of interdependent relationships proved crucial in connecting them to potential employers. Bridgeheads were identified as a particularly valuable resource through which information in respect to employment could be passed. Existing migrants acting in this capacity were able to pass information to potential migrant recruits in respect of employment opportunities whilst, at the same 
time, providing a form of guarantee for the employer that the recruit was suitable for employment.

To some extent, the findings in this paper stand in contradiction to previous research that has examined the role that networks play in defining the career trajectories of migrant workers in professional sport. A number of studies have concluded that networks are used as mechanisms through which athletes can avoid the costs that are incurred when retaining an agent. As many of the players interviewed as part of this study relied on an agent to broker their eventual migration in one way or another, the ability to tap into the flows of information available in networks should, for some players, be viewed as an additional strategy in the identification of employment opportunities that works in conjunction with any strategy that the player's agent might employ.

Arguably, networks were more important for recruiters than they were for players in the context of the Norwegian Tippeligaen. Given the prominent role that agents play in brokering the relationship between player and club, coaches and sporting directors were reliant on the information that flowed via networks to validate the information that they were receiving in respect of players from agents. It was generally accepted that agents could not always be trusted, predominantly as a result of what the respondents saw as mercenary motives and bias in respect of the players they represented. In this respect, the ability to supplement the information being provided by agents was crucial in assuring the quality of the player and their suitability for employment. Coaches and sporting directors regularly drew on the flows of information available in networks to learn more about potential recruits, their level of ability and how they might fit into the team and Norwegian football more broadly.

Being able to validate the information provided by agents was seen to be critical in a sporting context where clubs rarely retained the services of scouts. Without any formal mechanisms by which to confirm the information being provided to them, coaches and sporting directors relied on their contacts to corroborate what they were being told by more formal intermediaries. Players, it appeared, were viewed as being one of the most important resources in this 
regard as they could verify that the information provided in regards to a potential migrant recruit was accurate. Additionally, players were deemed likely only to recommend those recruits that would enhance the performance of the team. Thus, coaches and sporting directors thought it advantageous to take recommendations from players they trusted, as these players were likely to recommend recruits who would likely meet the demands of the job.

Validating the information provided by agents and securing recommendations from players were seen to be crucial recruiting strategies in an environment where coaches and sporting directors simply could not afford to recruit the wrong players. Tippeligaen clubs operate within very small budgets when compared to Europe's more established leagues and, as a result, making sound, well informed and educated recruiting decisions was seen to be crucial. These findings are more consistent with existing studies that have traced the value of networks in the recruitment of professional athletes in peripheral sporting contexts. A number of studies have shown that when recruiters are unable to scout potential recruits, typically as a result of financial limitation, then networks form a central part of the knowledge gathering process.

This analysis shows that networks play an important role in the recruitment of migrant workers to the Norwegian Tippeligaen. However, it also shows that networks do not operate in this particular context in the same ways as they may do in other sectors of the labour market. Rather than operating in an entirely informal sense where migrants have no contact with formal intermediaries, the recruitment of migrant workers to Tippeligaen clubs should be seen to be reflective of an interdependent mix of both formal and informal actors to mobilise migrant labour. What becomes clear in this particular context is that the reliance on networks differs between the players and the recruiters. These findings illustrate the importance of examining the recruiting process through the lens of both parties.

Future research should take into account the interdependence of employees and employers in the recruiting process. Exploring the recruiting process from the perspective of one group or the other will likely only tell part of 
the story. This study has shown how both groups are bonded to one another via multiple networks of interdependence; these networks facilitate important flows of information that ultimately enable the mobility of some workers. Further research should also seek to establish if the same approach to recruitment is identifiable in leagues of comparable quality to the Norwegian Tippeligaen and how recruiting processes might differ across a range of established and peripheral leagues in professional football's increasingly complex global architecture. Existing research argues that informal recruiting mechanisms are likely to be utilised more so in those leagues that are deemed to be less 'professional'. The findings from this study of a middle ranking European league show a mix of formal and informal approaches. Further research may wish to explore if more established leagues reflect more formal recruiting strategies, whilst peripheral ones rely more heavily on informal ones. 


\section{References}

Agergaard S and Ryba T (2014) Migration and Career Transitions in Professional Sports: Transnational Athletic Careers in a Psychological and Sociological Perspective. Sociology of Sport Journal 31(2): 228-247.

Andersson T and Carlsson D (2009) Football in Scandinavia: A fusion of welfare policy and the market. Soccer and Society 10(3): 299-304.

Bale J (1991) The Brawn Drain: Foreign Student-Athletes in American Universities. Urbana: University of Illinois Press.

Behtoui A (2008) Informal recruiting methods and disadvantages of immigrants in the Swedish labour market'. Journal of Ethnic and Migration Studies 34(3): 411-430.

Bohning WR (1984) Studies in International Labour Migration. Basingstoke: Macmillan.

Boyd M (1989) Family and personal networks in international migration: Recent developments and new agendas. International Migration Review 23(3): 638-670.

Chua V (2011) Social networks and labour market outcomes in a meritocracy. Social Networks 33(1): 1-11.

Deloitte (2013) Annual Review of Football Finance. London: Deloitte LLP.

Elliott R (2012) New Europe, new chances? The migration of professional footballers to Poland's Ekstraklasa. International Review for the Sociology of Sport 48(6): 736-750.

Elliott R (2014a) Brits abroad: A case study analysis of three British footballers migrating to the Hungarian Soproni Liga. Soccer and Society 15(4): 517-534.

Elliott R (2014b) Football's Irish exodus: Examining the factors influencing Irish player migration to English professional leagues. International Review for the Sociology of Sport DOI: 10.1177/1012690213519786.

Elliott R and Maguire J (2011) 'Net-gains': informal recruiting, Canadian players and British professional ice hockey, in Maguire J and Falcous M (eds). Sport and Migration: Borders, Boundaries and Crossings. London: Routledge, pp.102-111.

Elliott R and Maguire J (2008) 'Getting Caught in the Net': Examining the Recruitment of Canadian Players in British Professional Ice Hockey. Journal of Sport and Social Issues 32(2): 158-176.

Engh M and Agergaard S (2013) Producing mobility through locality and visibility: Developing a transnational perspective on sports labour migration. Journal of Sport and Social Issues. DOI: 10.1177/1012690213509994.

Fischer A Reiner $M$ and Straubhaar $T$ (1997) Interdependencies Between Development and Migration in Hammar T Brochmann G Tamas K Faist T (eds) 
International Migration, Immobility and Development: Multidisciplinary Perspectives. Oxford: Berg, pp.91-132.

Gammelsaeter H (2009) The organization of professional football in Scandinavia. Soccer and Society 10(3-4): 305-323.

Giulietti C Schluter C and Wahba J (2013) With a lot of help from my friends: Social networks and immigrants in the UK. ESRC Centre for Population Change working paper Number 31. Southampton: Centre for Population Change.

Granovetter M (1995) Getting a job: A study of contact and careers. Chicago: University of Chicago Press.

Hognestad H (2009) Transglobal Scandinavian? Globalization and the contestation of identities in football. Soccer and Society 10(3-4): 358-373.

Jakobsen S-E Gammelsaeter H and Floysand A (2009) The spatial embeddedness of professional football clubs in Norway. Soccer and Society 10(2): 261-279.

Lin N (1999) Social networks and status attainment. Annual Review of Sociology 25: 467-487.

Magee J and Sugden J (2002) "The world at their feet": Professional football and international labour migration. Journal of Sport and Social Issues 26(4): 421-437.

Maguire J (1994) Preliminary observations of globalisation and the migration of sports labour. The Sociological Review 42(3): 452-480.

Marshall T (1989) Cultural Aspects of Job Hunting. London: British Refugee Council.

McCollum D and Apsite-Berina E (2014) Recruitment through migrant social networks from Latvia to the United Kingdom: Motivations, processes and developments. Migration Letters 12(1): 50-66.

McPherson M Smith-Lovin L and Cook J (2001) Birds of a feather: Homophily in social networks. Annual Review of Sociology 27: 415-444.

McCree R (2014) Student athletic migration from Trinidad and Tobago: The case of women's soccer, in Agergaard S and Tiesler N-C Women, Soccer and Transnational Migration. London: Routledge, pp. 73-85.

Meyer J-B (2001) Network approach versus brain drain: Lessons from the diaspora. International Migration 39(5): 91-110.

Molnar G (2006) Mapping Migrations: Hungary Related Migrations of Professional Footballers after the Collapse of Communism. Soccer and Society 7(4): 463-485. 
Norges Fotballforbund. (2013). Klubblisens 2013 (in Norwegian) [online] Available at

http://www.fotball.no/Documents/Bilder/NFF/2014/Klubblisens\%20medapre sentasjon\%202013.pdf

Norges Fotballforbund. (2014). NFF årsrapport 2013 (in Norwegian) [online] Available at:

http://www.fotball.no/nff/NFF-nyheter/2014/NFF-arsrapport-2013/

Poli R (2014) International migration of professional footballers. In: Goddard J and Sloane P (eds.) Handbook on the Economics of Professional Football. Cheltenham: Edward Elgar Publishing Limited, pp.227-236.

Poli R (2010) Agents and Intermediaries in Chadwick S and Hamil S (eds.) Managing Football: An International Perspective. Oxford: Butterworth Heinemann, pp.201-216.

Rainer H and Siedler T (2009) The role of social networks in determining migration and labour market outcomes. Economics in transition 17(4): 739-767.

Roderick M (2014) Sociology in Sport: A very precarious profession uncertainty in the working lives of professional footballers, in Neil R Hanton $S$ Fleming S and Wilson K (eds). The Research Process in Sport, Exercise and Health: Case Studies of Active Researchers. London: Routledge, pp. 81-99.

Roderick M (2006) The Work of Professional Football: A Labour of Love? London: Routledge.

Shah N and Menon I (1999) Chain migration through the social network: Experience of labour migrants in Kuwait. International Migration 37(2): 361382.

Sumption M (2009) Social networks and Polish Immigration to the UK. Institute for Public Policy Research Economics of Migration Working Paper 5. London: IPPR.

Tiesler N-C (2014) Three types of transnational player: Differing women's football mobility projects in core and developing countries. ICS working paper 2014/01. Lisbon: Instituto de Ciências Sociais da Universidade de Lisboa.

Transerfermarkt.co.uk. (2014). Tippeligaen. Foreign players [online] Available at: http://www.transfermarkt.co.uk/tippeligaen/gastarbeiter/wettbewerb/NO1 